\title{
A MOLECULAR MEDICINE DATABASE
}

\author{
Kenneth S. Warren, M.D., Deputy Editor \\ Molecular Medicine
}

Molecular Medicine initiated a database of articles on the subject in the second issue of this journal (January 1995) in the belief that it would be a useful source of information for those engaged in this relatively new and rapidly growing field of medical research.

Historically, molecular medicine may be said to have had its inception in 1944 when three physicians, working at The Rockefeller Institute, revealed that the factor that transformed pneumococcus to a virulent state was DNA (1). Almost a decade later, a biologist and a physicist discovered the molecular structure of DNA (2), and discussed its striking "genetical" implications (3). In the 1970s the development of the techniques of recombinant DNA enabled the manipulation of the genetic makeup of living cells, leading to the biotechnology revolution (4). The cells studied evolved from bacteria and yeasts to those of mammalian origin. In vivo systems progressed from fruit flies to elegant worms, and eventually to mice, rats, and other mammals. In the last 10 years the application of these systems to human disease has been burgeoning, resulting in a distinctive field of biomedical research called molecular medicine.

The molecular approach to medical research is of particular importance because all of the functions of the body in health and disease are essentially controlled by macromolecules such as enzymes and receptors. Furthermore, diagnostic, therapeutic, and prophylactic molecules function largely by interacting with these macromolecules. We consider papers to fall into the category of molecular medicine, therefore, if their subject of matter clearly involves molecules on the mechanistic and/or intervention level, and if it is relevant to human disease.

With respect to the development of a database for molecular medicine, my experience in modern computerized systems began in the early 1960s, the end result being one of the first digitized bibliographies of an entire medical literature from its inception in 1852 (5). This was soon followed by the development of a qualitative core of the complete literature selected by a board of 50 experts (6). In conjunction with Professor William Goffman, mathematician and Dean of the School of Library Sciences at Case Western Reserve University, research on the above databases, plus an exhaustive examination of its $4 \%$ core, and analysis of other medical and scientific literature databases were made (7). This led to the ineluctable conclusion that only a very small proportion of the total published material was methodologically sound and of significant value. Furthermore, it was found that most information of value comes from a relatively small group of scientists, working largely at major research institutions and doing their best to publish in a small core of prestigious journals.

The principles learned from the above investigations have enabled us to produce a wieldy molecular medicine database which provides citations largely from the small core of the best journals. Our starting point for establishing the journals to be included in the database was the Science Citation Index's annually updated Journal Citation Reports. The initial journals, selected from all relevant scientific and clinical categories on the basis of their impact factors (total citations/ total papers published annually) numbered 50. A survey over a period of 6 months enabled us to weed out 26 journals, which carried no relevant papers, and to add two new and highly relevant journals. This iterative process will be ongoing. At present, we are surveying 26 journals (less than $1 \%$ of the 3,400 biomedical journals in the MEDLINE database), which produce approximately 1,600 papers per month. In order to ensure that our database is not only efficient but inclusive we need to turn to you, the readers of 
Molecular Medicine, to alert us to important, highquality papers (in any journal) that should be included; after review, they will be added to the database in subsequent issues of Molecular Medicine.

For the 4-month period (September-December 1994) covered in the January and March issues of Molecular Medicine, 255 citations were recovered. The largest number of relevant articles, 53, was found in the Proceedings of the $\mathrm{Na}$ tional Academy of Sciences, followed by 36 in the Journal of Immunology, 18 in Science, 16 in the Journal of Experimental Medicine, 15 in the Journal of Clinical Investigation, and 14 in Nature. Of the great weekly medical journals, Lancet had only five and the New England Journal of Medicine, 2. Eight high-impact journals were originally selected for surveillance because they contained the word "molecular" in their titles, but seven of them had no papers whose subject matter we could define as molecular medicine over a 4-month period.

Please remember that we are providing a molecular medicine database as a service to you, the readers. We would be grateful, therefore, for your input, including articles missed, suggestions, and comments.

\section{REFERENCES}

1. Avery OT, MacLeod CM, MacCarty M. (1944) Studies on the chemical nature of the substance inducing transformation of pneumococcal types. J. Exp. Med. 36: 137-158.

2. Watson JD, Crick FHC. (1953) Molecular structure of nucleic acids: A structure for deoxyribose nucleic acid. Nature 171: 737-738.

3. Crick FHC, Watson JD. (1953) Genetical implications of the structure of deoxyribonucleic acid. Nature 171: 964-967.

4. Cohen S, Chang H, Boyer H, Helling R. (1973) Construction of biologically functional bacterial plasmids in vitro. Proc. Natl. Acad. Sci. U.S.A. 70: 3240-3244.

5. Warren KS, Newill VA. (1967) Schistosomiasis: A Bibliography of the World's Literature from 1852-1962. The Press of Western Reserve University, Cleveland.

6. Warren KS. (1973) Schistosomiasis: The Evolution of a Medical Literature. The MIT Press, Cambridge.

7. Goffman W, Warren KS. (1980) Scientific Information Systems and the Principle of Selectivity. Praeger, New York. 